\title{
ENSAYO
}

\section{INFLUENCIA PROTESTANTE E INQUISICIÓN EN LA ALCALDÍA MAYOR DE SONSONATE: SIGLOS XVI Y XVIII}

\author{
Alexis Mijael Coto Argueta \\ Egresado de la Carrera de Teología \\ Facultad de Ciencias Sociales \\ Universidad Evangélica de El Salvador \\ Recibido: 05/10/2015 \\ Aceptado: 12/12/2015
}

\section{RESUMEN}

En el artículo se da cuenta del proceso de rastreo, paleografía, transcripción y análisis de un expediente del Tribunal de la Inquisición abierto en 1767 en contra de don Carlos de Lorenzana bajo el cargo de herejía y apostasía. El caso fue registrado en Sonsonate. Los resultados obtenidos demuestran que durante los siglos XVI, XVII, XVIII ya circulaban ideas protestantes -algunas de clara influencia cátara- por estas tierras, las cuales estaban siendo diseminadas por extranjeros que llegaban al Reino de Guatemala como consecuencia del intenso comercio legal o ilegal que se desarrollaba alrededor del puerto de Acajutla. La copia del documento se encuentra resguardado en el Archivo General de la Nación de El Salvador.

Palabras clave: Inquisición, acusaciones, herejía, protestantismo, Sonsonate (La Trinidad), puerto de Acajutla, cátaros, teología, El Salvador.

\section{PROTESTANT INFLUENCE AND INQUISITION IN SONSONATE CITY HALL (CENTURIES XVI AND XVIII)}

\section{ABSTRACT}

This article gives an account of the tracking process, palaeography, transcription and analysis of an Inquisition Court file opened in 1767 against don Carlos de Lorenzana under the charges of heresy and apostasy. The case was reported in Sonsonate. The results obtained show that during the centuries XVI and XVIII protestant ideas were already circulating through these lands, some with a clear Cathars influence. These ideas were being propagated by foreigners who came to the Kingdom of Guatemala as result of the intense legal and illegal trade developed around Acajutla port. The copy of the document is safeguarded by the National Archives of El Salvador.

KEY WORDS: Inquisition, accusations, heresy, Protestantism, Sonsonate (La Trinidad), Acajutla port, Cathars, theology, El Salvador. 
La investigación dio inicio con la búsqueda de información en los registros del Archivo General de la Nación de El Salvador (AGN), más específicamente en el "Repositorio de divulgación del Archivo General de la Nación", ${ }^{1}$ publicado por Concultura en el año 2003. En este documento se encuentran consignados algunos de los expedientes de la Inquisición sobre nuestro país, que se agruparon bajo el título "Documentos relativos a la actuación del tribunal del Santo Oficio de la Inquisición en la alcaldía mayor de Sonsonate y la provincia de San Salvador".

La publicación hace mención a al menos 182 casos que tuvieron lugar en la provincia de San Salvador durante un periodo aproximado de 250 años, entre 1557 y 1800. Es importante mencionar que dichos registros son solo copia de los manuscritos originales que se encuentran en el AGN de México.

Lo que la investigación quería determinar era si entre esos documentos existían expedientes relacionados con personas acusadas directamente por herejía protestante; y en efecto, se encontraron y retomaron del Repositorio los registros de tres casos situados en Sonsonate, San Salvador y Zacatecoluca, que se detallan a continuación:

Zacatecoluca, 1577: se relaciona con una denuncia en contra de García de Molina a causa de proposiciones heréticas.

San Salvador, 1783: relaciona una denuncia espontánea que realizó Pedro Velásquez ante el comisario de esa ciudad, quien era mulato de calidad, de oficio labrador, por haber incurrido en el crimen de herejía mixta.

Sonsonate, 1767: contra Don Carlos de Lorenzana, quien fue denunciado por su mujer, Doña Juana Fernández, por hereje apóstata.
Debido a que los registros del Repositorio son solo copia de los manuscritos originales -de una antigüedad aproximada de al menos 250 años y se encuentran escritos en castellano antiguo-, se dificultó el acceso a dos de los casos, por lo que la investigación se redujo a profundizar en el caso de herejía denunciada en Sonsonate en 1767, que se encontraba en mejores condiciones. El proceso requirió de un trabajo previo de paleografía y transcripción, y del cual se presentan los siguientes resultados.

\section{Sonsonate, 1767: acusación de herejía y apostasía $^{2}$}

La acusación la realizó doña Juana Fernández, que en "descanso de su conciencia”, inició un juicio formal ante el Santo Oficio de la Inquisición, y quien por no saber escribir tuvo que dictar los hechos ante Alonzo Cortes, Comisario del "Santo Oficio".

Doña Juana denuncia que su esposo, don Carlos de Lorenzana, en diversas ocasiones se reunió con un inglés nombrado únicamente como don Joseph, y que en las tales reuniones y conversaciones abordaban temas relacionados con la quema de bulas papales y la desobediencia a las autoridades católico-romanas; en tales pláticas también se desaprobaban las prácticas católicas, y de cómo don Joseph estaba en desacuerdo con diferentes puntos de la doctrina católica, tales como la obediencia al papa, las indulgencias y la adoración a la cruz. Doña Juana Fernández denuncia lo dicho por el inglés de la siguiente manera:

“...que qué potestad había de tener un hombre como nosotros para conceder indulgencias, ni para que se sujetaran a él, en cuia conversación dijo que cómo habíamos de adorar la cruz solo porque [Cristo] había arrimado [a ella] su cuerpo, 
que eran idolatras los cristianos adorando imágenes de palo, que cuándo había que haber tales imágenes, que los ingleses solo en Dios creían...

Ahora bien, al parecer las reuniones no eran casuales, sino habituales. De acuerdo con la denuncia de doña Juana, dicho inglés, en conjunto con don Carlos y quizás otras personas, tenían reuniones periódicamente en donde hablaban de los temas referentes a "la ley de los ingleses", refiriéndose con esto a sus creencias religiosas.

"...y si denuncia que el mismo día habiendo regresado de dicha hacienda de Santa Bárbara a su sitio de [la] hacienda llamado el [Mascarado] preguntándole la que denuncia a su marido, que porqué diría el inglés lo [ya] referido, le respondió su marido, que porque era [correcto], y que era mejor ley la de los ingleses, que nosotros idolatrábamos en las imágenes, y que ellos [seguían] buena ley... que solo por eso se había de ir a su tierra, que era más suave su ley, que era la ley verdadera por ser la antigua y primera. Denuncia así mismo que en unas cuatro ocasiones en distintos tiempos, una que amucho tiempo que no puede hacer acuerdos, otras dos en dicho sitio llamado el [Mascarado] después de dicha conversación, y la última que [sería], según hace acuerdo en el presente mes de marzo, y [febrero] próximo pasado..."

Las personas que se reunían con este inglés en diferentes lugares de Sonsonate, Izalco (y quizás también en otros partes) no solo lo escuchaban, sino que también terminaban convencidas por los argumentos esgrimidos por don Joseph:

“...en esa misma ocasión preguntándole, la que denuncia a su marido, qué le parecía de lo que decía el inglés, le respondió que era verdad, que decía bien, que se convencía con sus palabras..."
Por otra parte, el inglés Joseph no era alguien que estaba de paso por Sonsonate. Según el documento, las primeras reuniones tuvieron lugar en el año de 1763 , es decir 4 años antes de que Doña Juana se decidiera a presentar la denuncia:

“...en el mes de diciembre del año sesenta y [tres] fue la primera vez que la que denuncia hoyó hablar a dicho inglés don Joseph con su marido don Carlos sobre los mismos puntos de la obediencia al papa, de la adoración a las imágenes, y sobre el punto de indulgencias y especialmente sobre la adoración de la cruz, y añadió le oyó decir en esa misma conversación, que en su tierra no creían que había purgatorio ni infierno..."

La última afirmación de doña Juana sobre la no existencia del purgatorio y del infierno conduce a investigar sobre la procedencia de aquellas personas e ideas protestantes. En realidad, estas ideas eran parte de los principios de un fuerte movimiento que prosperó entre los siglos XI y XII: los llamados albigenses o cátaros. Los cátaros se caracterizaban por ser una comunidad pobre que se nutría de las enseñanzas de la Iglesia primitiva de los apóstoles. Entre sus creencias negaban tajantemente la naturaleza divina de Jesús y rechazaban rituales como la eucaristía y la veneración a la cruz.

Aunque los cátaros eran dualistas y defendían la existencia de las fuerzas buenas y las fuerzas malas, no creían en el infierno ni en el purgatorio. Después de varias cruzadas por parte de las autoridades de la Iglesia en contra de este grupo disidente, fue desapareciendo poco a poco, pero el catarismo ya había dejado una enorme huella en la historia y movimientos cristianos antes de iniciarse la Reforma luterana. ${ }^{3}$ 
El catarismo, en definitiva, dejó una profunda huella espiritual que perduró a través de los tiempos, llegando hasta el siglo XVI, donde vemos ciertos parecidos con la aparición del protestantismo. Sin embargo, su pasado se hunde en lo más remoto de la historia, en el zoroastrismo persa y el maniqueísmo, y su presente se halla, aunque transformado, en las religiones protestantes, especialmente en el calvinismo.

La información descubierta sobre este caso, por medio de los testimonios de la acusadora doña Juana Fernández, lleva a pensar que para el siglo XVIII la influencia del protestantismo ya era fuerte o significativa en tierras salvadoreñas. Esto nos llevó a la búsqueda de más información acerca de otros casos de acusación por herejía durante el período colonial.

En un artículo titulado "Etapas de la Inquisición en Centro América"4, se cita al historiador salvadoreño Pedro Escalante Arce, quien ha realizado algunas investigaciones sobre el tema de la Inquisición en El Salvador:

"Durante su primera etapa, la actividad inquisitorial se concentró en extinguir la herejía luterana, llegando a quemar en Sonsonate, El Salvador, a Guillermo Cornields, un irlandés ex pirata y barbero, de 24 o 25 años, el único condenado a muerte por el Tribunal de la Nueva España, que haya tenido relación con el Reino de Guatemala. Su pasado protestante lo mató; no sólo se le condenó como tal, sino como enemigo político que podía contagiar a sus semejantes con ideas peligrosas $y$ subversivas de las sectas disidentes de Roma. Caso acontecido en 1574".

Se concertó una entrevista con Pedro Escalante Arce, actual Director de la Academia Salvadoreña de la Historia, quien ha dedicado varios años de su vida a investigar acerca de este tema en los archivos contenidos en el AGN de México, en la Biblioteca Centroamericana de Guatemala y en la Biblioteca de Sevilla, España, así como en diversos museos de la Inquisición en México, Perú y España.

En dicha entrevista se conversó respecto de sus investigaciones sobre la Inquisición, y se le planteó sobre los casos de herejía y las ideas protestantes ya mencionadas, a lo cual comentó que no había puesto mucho cuidado a tales temáticas, pues su interés investigativo no tenía mucho que ver con el ámbito religioso, sino más bien con los procesos legales de la Inquisición ocurridos en tierras salvadoreñas.

Respecto a los casos contenidos en el AGN de El Salvador, Escalante Arce reafirmó que son solo una pequeña muestra de la totalidad que están resguardados en el AGN de México, donde él ha investigado y paleografiado algunos de ellos, como el del pirata irlandés Guillermo Cornields, el de la actividad judía de la familia Carvajal, el del alcalde mayor de la villa de La Trinidad (Sonsonate) y Acajutla, Xuares de Toledo, entre otros.

Durante esta entrevista, Escalante Arce esclareció los motivos por los cuales existían diversas influencias culturales y/o religiosas en la zona de Sonsonate:

En La Trinidad (actual Sonsonate) para inicios del siglo XVI ya existía una fuerte presencia de judíos, principalmente por razones comerciales que se escondían entre la población de ese tiempo y que seguían las prácticas católico-romanas para no levantar sospechas de sus creencias.

Seguramente no solo existía la presencia de judíos, sino también de ingleses, 
irlandeses, portugueses, entre otros, debido al fuerte comercio en La Trinidad y Acajutla. Tal como lo describe la Academia Salvadoreña de la Historia ${ }^{5}$ :

“En 1553, surgió la villa de La Trinidad, asentada a orillas del río Cenzúnat, Cenzónatl, o Sensunapán, nombre indígena que llegaría a sustituir al original español, con el nombre de bautizo aumentado más adelante a "Santísima Trinidad". Una villa establecida para mercaderes, dedicada a ser emporio de comercio con su puerto anexo, Acajutla, los cuales incluso llegarían a confundirse, porque en muchas cartas geográficas Sonsonate aparecerá como puerto. La Trinidad brotó de su matriz izalqueña, como villa de españoles comerciantes en cacao".

Lo confirma también otro caso contenido en el Repositorio del AGN de El Salvador ${ }^{6}$, en donde se relaciona una acusación por brujería de 1634, en Sonsonate, en contra de Sebastián, un "negro", quien seguramente fue traído en calidad de esclavo con el propósito de ser vendido.

La entrevista proporcionó también valiosa información respecto a la Inquisición en El Salvador, y colocó en el contexto adecuado la afluencia de personas extranjeras en tierras salvadoreñas. De hecho, la siguiente exposición de otro caso investigador por la Inquisición, ha sido tomada del libro Códice Sonsonate, escrito por Escalante Arce:

\section{Caso del irlandés pirata acusado de ser luterano (Sonsonate, 1574) ${ }^{7}$}

En el libro Códice Sonsonate se presentan los resultados del trabajo de transcripción del caso de un joven barbero y cirujano que residía en la región salvadoreña, por el siglo XVI, llamado Guillermo Cornields, de origen irlandés. Cornields era un hombre de aproximadamente 25 años quien junto a su esposa vivían en La Trinidad; a pesar de su aspecto nórdico, había sido aceptado por los moradores de esas tierras debido a que siempre cumplía con sus obligaciones religiosas, además de que ya se sabía que los irlandeses eran católicos amigos de España, por lo cual no habían sospechas de que pudiera ser una amenaza para la religión oficial en ese lugar.

Sin embargo, a Guillermo lo seguía un pasado oscuro, que era una de sus principales preocupaciones, pues hacía unos 6 años había estado enlistado en la tripulación del corsario inglés Jonh Hawkins, derrotado en una batalla en México en septiembre de 1568. Como se sabe, los piratas transportaban mercancías de forma ilegal a los diferentes puertos de las tierras de la Nueva España; sin embargo no solo transportaban mercadería sino también diversas culturas y creencias, pues muchos de estos piratas iban a las islas del Caribe a comprar esclavos negros para luego poder venderlos en estas regiones.

Cornields fue uno de los tantos tripulantes abandonados por el pirata Hawkins después de su huida por la derrota en 1568 por embarcaciones españolas. Cornields junto a otros tripulantes lograron escapar y huir de sus perseguidores, llegando a refugiarse primero en México, donde aprendió el oficio de cirujano-barbero, y luego emigró hacia al sur de Guatemala, y se estableció en La Trinidad.

Después de un par de años, en 1574, Cornields fue extraditado a la ciudad de México por órdenes del tribunal de la Santa Inquisición. Ahí se estaba enjuiciando a todos aquellos que habían llegado con Hawkins, pues la mayoría eran ingleses protestantes y piratas. Con la ayuda de testimonios de otros piratas ex compañeros del irlandés e investigaciones del Santo Oficio, llegaron a su ubicación 
en La Trinidad y ordenaron capturarlo a él y a sus bienes, que eran pocos, dejando a su esposa embarazada. En el año 1575, junto a otros que pagaban alguna condena, Guillermo Cornields fue quemado en la hoguera frente a la capilla de San José del convento de Santo Domingo.

Del acceso y análisis de cada uno de los casos antes citados surgieron interrogantes como: ¿quién era este inglés Joseph y porqué razones estaba en estas tierras?, ¿cuáles son los registros más antiguos que se tienen en El Salvador de la llegada de culturas como la inglesa, irlandesa, judía, entre otras?, ¿qué hacían los piratas en tierras salvadoreñas en el siglo XVI?, ¿por qué la existencia de tanta diversidad cultural en la zona de Sonsonate y San Salvador?, y ¿cuáles fueron las primeras ideas e influencias protestantes en nuestro país?

El caso del irlandés Cornields demuestra que para mediados del siglo XVI ya existía la presencia de ideas de otras culturas e influencias protestantes esparcidas por hombres y mujeres que habían llegado a nuestro país por diversas razones, quienes además debían vivir en una especie de clandestinidad, ocultando su verdadera identidad. Era muy arriesgado para ellos en los tiempos de la Inquisición, donde una pequeña sospecha podía convertirse en motivo de juicio para la persona. Asimismo, la venta de esclavos de culturas africanas, por parte de los piratas, insertaba las creencias en cuanto al chamanismo, brujerías, entre otros rituales.

En el caso de 1767 de Sonsonate, en relación a las afirmaciones del inglés llamado Joseph, respecto a la quema de bulas papales y la desobediencia a las autoridades religiosas, a primera vista responden a una teología que está lejos de ser parte de la católica, sino que más bien responden a la teología de algunas de las llamadas "sectas disidentes de Roma”, confirmando la sospecha de que el protestantismo y sus ideas teológicas ya estaban siendo esparcidas en tierras salvadoreñas por hombres que compartían sus ideas -al parecer- ya sin mucho temor a ser perseguidos y enjuiciados por la Inquisición.

En el caso del inglés Joseph, la expresión “... en su tierra no creían que había purgatorio ni infierno..." resulta muy interesante porque invita a reflexionar sobre ¿cuáles fueron las primeras ideas e influencias protestantes en nuestro país? Podría decirse que es muy probable que el inglés Joseph haya sido calvinista y que sus ideas teológicas estuvieran influenciadas por movimientos como el catarismo, que databan desde hacía ya 500 años atrás

La investigación lleva a conocer datos interesantes y novedosos para la historia de las iglesias evangélicas en El Salvador; ya que con la evidencia de la presencia de este tipo de ideas en los siglos XVI, XVII, XVIII se pone en duda quiénes fueron realmente los primeros misioneros y mártires dela iglesia evangélica en El Salvador, que abrieron las brechas culturales y el pensamiento de los pobladores salvadoreños.

Casos como los del inglés Joseph, quien compartía y convencía a otros de sus ideas protestantes -que respondían probablemente a una teología calvinista influenciado por movimientos cátaros del siglo XII-, era uno de varios que se dieron en las provincias centroamericanas.

Al encontrar que las ideas protestantes ya existían en tierras salvadoreñas mucho antes de la llegada de los llamados "primeros misioneros" en el siglo XIX, es posible pesar que para estos fuera más fácil hacer la labor evangelizadora, por el hecho 
de existir indicios o tener conocimiento de personas que habían sido enjuiciadas o muertas por la Inquisición a causa de compartir sus ideas religiosas y además posiblemente ya se encontraban personas que siguieran estas creencias.

Es necesario reconocer a los verdaderos hombres y mujeres que abrieron la brecha y pensamiento de un pueblo ya golpeado y abusado, tanto de forma política como religiosa; fantasmas de quienes no se sabe mucho pero que estuvieron y murieron en tierras centroamericanas, de quienes no se hace referencia pero que de alguna manera facilitaron la llegada de los "primeros misioneros" para la proclamación del evangelio en el siglo XIX.

Para posteriores investigaciones o ampliación de ésta, referente al tema de la Inquisición en El Salvador, es necesario accesar a los manuscritos o archivos resguardados en los diferentes países donde se estableció el Santo Oficio, entre ellos España, México, Perú o Guatemala. Se recomienda además a los futuros investigadores una formación en paleografía a efecto de tener mayor acceso y profundidad en los documentos relacionados a la Inquisición.

\section{FUENTES CONSULTADAS}

1. Consejo Nacional para la Cultura y el Arte (CONCULTURA). Repositorio. Revista de Divulgación del Archivo General de la Nación. 2003; III época (1): 137-151.

2. Archivo General de la Nación (AGN). San Salvador de Guatemala. Año 1767; Caja 4, Exp. 4.

3. Gabrielbernat [internet]. Miami: Bernardo Gui; [actualizado el 2002. Citado el 20 de mayo]. Disponible en http://www.gabrielbernat.es/ espana/inquisicion/ie/delitos/albigenses/albigenses.html

4. Sin autor. "Etapas de la Inquisición en Centroamérica (1569-1820)”. El nuevo diario. 2010.

5. Academia Salvadoreña de la Historia. "Fundación de Sonsonate". La Prensa Gráfica. 2012.

6. Archivo General de la Nación (AGN). Sonsonate. Año 1634, Exp. 26.

7. Escalante, Pedro. Códice Sonsonate, Crónicas Hispánicas. Vol. 1. Ed. 1. San Salvador: Dirección de Publicaciones e Impresos (DPI), 1992. 